\title{
Pseudoaminopterin syndrome
}

INSERM

\section{Source}

INSERM. (1999). Orphanet: an online rare disease and orphan drug data base.

Pseudoaminopterin syndrome. ORPHA:221120

Pseudoaminopterin syndrome is a developmental anomalies syndrome that resembles the aminopterin embryopathy (see this term) without history of fetal exposure to aminopterin. It is characterized by skull (craniosynostosis and poorly mineralized cranial vault), dysmorphic (ocular hypertelorism, palpebral fissure anomalies, micrognathia cleft lip and/or high arched palate and small and low set/rotated ears) and limb (brachydactyly, syndactyly and clinodactyly) anomalies, associated with mild-to-moderate intellectual deficit and short stature. 